Article

\title{
Novel Advanced Composite Bamboo Structural Members with Bio-Based and Synthetic Matrices for Sustainable Construction
}

\author{
Amir Mofidi *(D), Judith Abila and Jackson Tsz Ming Ng \\ School of Engineering, Newcastle University, Newcastle upon Tyne NE1 7RU, UK; \\ Judyabila.ja@gmail.com (J.A.); jacksontmng@gmail.com (J.T.M.N.) \\ * Correspondence: amir.mofidi@ncl.ac.uk
}

Received: 12 February 2020; Accepted: 20 March 2020; Published: 22 March 2020

check for updates

\begin{abstract}
This paper experimentally investigates the properties of unprecedented new advanced composite structural members in compressions made of bamboo culms formed with different bio-based and synthetic matrices. Due to extensive $\mathrm{CO}_{2}$ emissions corresponded to the production of construction materials, it is essential to produce high-performance environmental-friendly construction materials from bio-based renewable resources such as bamboo. However, the use of bamboo culms in construction has been hindered by their inherent specific geometric hollow shape. To address this issue, small-diameter bamboo species were used in this study to form solid structural composite cross-sections to desired shapes. An experimental study was conducted on the compressive properties of six composite structural members made of commonly available bamboo species (Phyllostachys edulis or Moso) with different matrices including a bio-based furan resin, a cementitious grout, and epoxy. In order to prevent premature buckling of bamboo components within the engineered columns, and in an attempt to propose a bio-based structural column, three layers of hemp wrap where applied to provide confinement for bamboo culms. The results of the tests confirm that the bamboo-furan and bamboo-grout composite columns both have the potential to reach a remarkable compressive strength of $30 \mathrm{MPa}$. However, the bamboo-epoxy composite specimen, considering the excellent mechanical properties of the epoxy matrix, delivered a benchmark to demonstrate the potentials of bamboo-based structural sections by reaching $76 \mathrm{MPa}$ compressive strength before crushing. The bamboo-epoxy composite provided new prospects for future work on the $100 \%$ bio-based versions of the bamboo-based sections with improved bio-matrices (by using bio-epoxy and improved furan resins with compatible mixes) and innovative confinement types. With the promising results of this study, there is a real opportunity of creating contemporary engineered bamboo-based structures as a sustainable replacement to the existing steel, concrete and timber structures.
\end{abstract}

Keywords: green construction materials; sustainable construction; bio-based construction materials; bio-composites for construction; structural bamboo; hemp fabric; furan resin

\section{Introduction}

The world's population growth rate has never been higher than the current rate which has led to extreme urbanization rates worldwide [1]. It is predicted that, only in the developing territories, over 2 billion people will be migrating to cities in the next thirty years [2]. Subsequently, enormous carbon emissions corresponded to building accommodations and other infrastructure for the moving population will be anticipated. Meanwhile, already the world is facing the highest rate of greenhouse gases emissions that have ever been experienced [3]. Greenhouse gases are one of the main causes of the climate change that led to the increased rates of droughts, hurricanes, and floods around the world 
lately [4]. One of the main contributors to the greenhouse effects, with $30 \%$ carbon footprint, is the building industry [5].

Different renewable, low-cost, and sustainable building material alternatives have been proposed to replace steel, concrete, and plastics. Bamboo and hemp are among the most promising organic building materials that can become the future mainstreams in construction industry provided sufficient research be conducted on their proper standardized use [6].

Among available organic building materials, bamboo is a competitive, cost-effective, and the ecologically-responsible option to traditional non-renewable construction materials. Bamboo is a renewable resource with a negative carbon footprint, though its global application in the construction industry is towards sustainable construction objectives [3]. Interestingly, different species of bamboo grow in the tropical and subtropical climates, covering most developing countries that own the highest rates of population growth and urbanization [1]. To put this in perspective, bamboo forests are broadly dispersed in countries with tropical, subtropical, and temperate climates in the Asia Pacific (ca. 67\%), the Americas (ca. 30\%) and Africa (ca. 3\%) [7].

Bamboo is a giant fast-growing grass, native to Asia, Africa, America and Oceania, that as evergreen perennial flowering plants in the subfamily Bambusoideae of the grass family Poaceae (Gramineae). Bambusoideae subfamily comprises 1575 species altogether [8] in three different and genetically-analysed lineages: tropical woody bamboos (Bambuseae), temperate woody bamboos (Arundinarieae) and herbaceous bamboos (Olyreae) [9]. The tropical woody bamboos comprise approximately 800 species distributed largely in the Paleotropics and Neotropics. The temperate woody bamboos with more than 500 species distributed mainly in the North Temperate zone, while the herbaceous bamboos, does not hold much of industrial use, with around 120 species restricted mostly to the Americas [10]. Only less than 100 bamboo species are appropriate for structural uses [11]. The most important species used in construction are; Moso bamboo (Phyllostachys edulis, formerly Phyllostachys pubescens, a temperate bamboo), Guadua (Guadua angustifolia, a tropical woody species that is the largest Neotropical bamboo), and Dendrocalamus asper (Giant bamboo, a tropical woody bamboo native to Southeast Asia). The mentioned bamboo species, hereafter constructional bamboo, grow rapidly of up to $250 \mathrm{~mm}$ per day, culm diameter of 100 to $180 \mathrm{~mm}$ and height of 12 to $20 \mathrm{~m}$ [12]. From a technical point of view, constructional bamboo can reach its maximum structural strength in three years [13]. Some species of constructional bamboo have shown tensile strength of about $400 \mathrm{MPa}$ while bamboo fibres can reach a massive tensile strength of $1000 \mathrm{MPa}$ [14-16]. This means that, if used properly, constructional bamboo fibres have the potential to have a superior mechanical behaviour to timber with a lower weight to strength ratio than construction steel.

Recently, there has been growing interest in the production of reliable bamboo-based materials as sustainable, economical, and environmentally friendly alternatives of existing construction materials [17]. The fact that bamboo grows rapidly and matures to maximum strength within 3-5 years allows the material to be harvested more quickly than conventional organic building materials such as timber [18]. Accordingly, bamboo forests have up to four times the carbon density per hectare of spruce forests over the long term. It should be noted that bamboo is found in developing areas of the world where timber recourses are limited, and steel production is scarce [19].

It is interesting to know that the carbon footprint to harvest, transport, process and produce industrially processed bamboo elements is- $500 \mathrm{~kg} / \mathrm{ton}$ [3]. This forms a vivid contrast to many building materials such as concrete and steel, whose productions release a high level of greenhouse gases and consumes a vast amount of energy. For instance, the carbon footprint of sustainable hardwood, concrete, cement, steel, and unsustainable hardwood are $-10,+180,+1250,+2020$, and $+3440 \mathrm{~kg} / \mathrm{Ton}$, respectively [3].

With a sustainable industrial approach, rapid growth and reproduction of bamboo through rhizomes results in a very valuable carbon sink in well-organized forests. Bamboo can reduce pressure on other forest resources to prevent deforestation, can help recover degraded lands, and may substitute energy-intensive construction products such as steel and concrete [18]. 
Bamboo has a long history of use in construction, crafts and for food and medicinal purposes. The current focus on sustainable development in the world has led to increased interest in the application of bamboo in modern construction. According to Food and Agriculture Organisation (FAO), approximately over one billion people in the world live in traditional bamboo houses while about 2.5 million people rely on bamboo as a source of living [20]. Bamboo forests are the most readily available resources in many communities that can solve one of the most vital human glitches, i.e., the housing problem. Constructional bamboo can be the preferred choice of material in construction among sustainable solutions due to its lower price, faster growth rate and superior mechanical properties compared to traditional timber species [21]. So far, there have been few attempts to build bamboo-based engineered buildings and footbridges e.g., [22-24]. However, bamboo has not become a mainstream construction material and the use of bamboo in the building industry is presently restricted to traditional and vernacular applications [25].

\section{Literature Review}

Despite its many advantages, including excellent mechanical properties, rapid growth and reproduction, cost-effectiveness, and environmental-friendliness. Some technical issues hindered the widespread use of bamboo in the construction industry. This is mainly due to the fact that the natural shape of raw bamboo culms cannot be easily applied in industrial construction, which limits the direct application of the raw bamboo culms into non-engineered construction [17]. The geometrical limitations such as the hollow shape of bamboo make it challenging to develop versatile, practical, easily deployable and resilient structural members for larger structures under heavy loads. Although, the hollow shape of bamboo provides an efficient shape in terms of its flexural mechanical characteristics, it keeps the member prone to local buckling of bamboo fibres under compressive stresses. Meanwhile, the natural shape limits the designers' options to the existing shape of bamboo. The natural nearly circular shape of bamboo's cross-section makes it difficult to provide proper connections at the joints. Hence, regardless of the bamboo culms remarkable mechanical properties, the natural shape of bamboo restricts bamboo's extensive use in the building industry. To increase their use in construction, sustainable structural bamboo products (SBP) or engineered bamboo products are developed in different composite material shapes that preserve advantages of the raw material to form a uniform section, while improving the raw material weaknesses and reducing the variability in properties. Engineering of bamboo involves applying industrialised manufacturing processes to produce various bamboo composite materials. Much research has gone into the production of composites using bamboo fibres and strips, however, most existing products are mainly used for secondary structural elements such as floors, claddings, ceilings and building envelopes e.g. $[16,17,21,26]$.

Until now, many studies have been conducted to investigate different possibilities to take advantage of bamboo's significant mechanical, eco-friendly and economical characteristics in construction. The most significant studies on the use of bamboo in construction can be mentioned as follows. Harries et al. [25] proposed standard test methods to classify the full-culm bamboo longitudinal splitting strengths. Sharma et al. [17] compared the mechanical properties of commercially available bamboo scrimber and laminated bamboo with those of timber and engineered timber products. They concluded that the bamboo products are competitive rivals to timber. Sharma et al. [26] studied the effect of, caramelizing and bleaching, two different methods to produced engineered bamboo laminates: on the mechanical properties of the members. The results of this investigation showed that the studied production methods can improve the mechanical properties of the bamboo products. Javadian et al. [1] investigated the bond behaviours of different coated bamboo strips to concrete when used as concrete reinforcement. Harries et al. [27] analysed the influence of culm section gradient on geometric properties of bamboo and the culms compression capacity. Huang et al. [28] compared the characteristics of bamboo with timber material when used as a building envelope. They concluded that bamboo had better heat storage and vapour resistance but worse heat transfer properties than those of timber counterparts. Trujilo and Malkowska [18] conducted around 390 tests to confirm the 
effectiveness of three proposed connection types (dowel embedment strength, slip modulus, and screw withdrawal capacity) for Guadua angustifolia species members.

It is clear that the potential of construction bamboo is promising and the adoption of bamboo as a mainstream structural material has several environmental benefits. The structural application of bamboo leads to the preservation of the world's scarce resources, conservation of energy and reduction of environmental pollution [23]. However, more extensive developments, hindered by its natural shape, can be achieved by systematic research on the standardized use of engineered bamboo that is currently lacking [25]. In this regard, this pilot study investigates, for the first time, the compressive mechanical behaviour of novel engineered bamboo composites that are manufactured to be used as load-bearing primary structural members in contemporary construction. To this end, parameters such as axial ductility, axial stiffness, absorbed energy, and the predicted axial capacity of the tested specimens are also investigated in this study.

\section{Materials and Experimental Methodology}

In this article, novel structural composite members made of full and split bamboo culms with different bio and synthetic matrices are proposed and tested in compression. As mentioned earlier, bamboo fibres are by nature strong in tension. However, due to the slender shape of the culms, the bamboo culms are prone to experience buckling in compression. In this regard, compressive axial testing has been chosen in this study to investigate the possibility of local buckling of bamboo culms in the composite sections under compressive loading. Circular framework fit several culms of bamboo with approximately $26 \mathrm{~mm}$ of diameter in the structural composite section before the matrix is applied. After the matrix is hardened, the columns are confined with hemp fabric saturated in the epoxy adhesive. Considering that bamboo is already strong in tension, the focus of the existing pilot study is on proposing economical and resilient bamboo-composite sections that can stand buckling of the bamboo culms under heavy compressive loads. To propose sustainable structural composite solutions, furan resin, a bio-based carbon-neutral polymer, was among the chosen matrices investigated in this study. This has led to the exploration of sustainable engineered bamboo sections made of bio-based resources to produce composites that are competitive to timber, concrete and steel in taking heavy structural loads. Another focus of the study was to design the composite sections in a way that, if required, the sections can be manufactured easily and affordably in desired shapes in construction sites using ordinary labour. To this end, circular columns are tested in compression made of full culm bamboo composite (FCB) and split culm bamboo composite (SCB) sections formed using different matrices of furan resin, cementitious grout, and epoxy. Confinement provided to the specimens consists of three layers of hemp wrap and epoxy resin. In order to study the effect of confinement on bamboo columns, an improved confinement type using a thin polyvinyl chloride (PVC) jacket was provided for one specimen. The outstanding unprecedented results of this study shows that there is great potential to use affordable, sustainable and robust bamboo-composite sections as heavy-duty structural members in multi-storey modern buildings.

The bamboo composite column specimens were tested under axial compression loading till failure. Overall, the experimental program (Table 1) involves six tests performed on bamboo-composite columns. The control specimen was not contained by a matrix, included eight 26-mm-diameter Moso bamboo culms bundled together with a sisal rope and was labelled CON. The full culm bamboo-composite columns were labelled FCB and the split column bamboo composites were named SCB. On the other hand, the specimens using a furan-based matrix were labelled FRN. Those formed with a cementitious grout were labelled GRT, and the specimen using an epoxy matrix was labelled EPX. Meanwhile, the specimens using three layers of hemp fabric confinement were labelled with $\mathrm{H}$. The specimen with improved PVC jacket confinement was labelled I. Thus, for instance, specimen FCB-FRN-H features a composite column with full culm bamboo formed in a furan-based matrix with three layers of hemp fabric confinement wrapped around the circular composite column. The specimen details are provided 
in Table 2, together with the labels used for each column hereafter. The variables to be studied in the experimental study are as follows:

- Behaviour of different bio-based and synthetic matrices in bamboo-based composite members using full and split bamboo culms.

- Influence of the confinement on the failure mode and compressive strength of FCB and SCB sections.

Table 1. Experimental results.

\begin{tabular}{|c|c|c|c|c|c|c|c|c|}
\hline Specimen & $\begin{array}{c}\text { Load at } \\
\text { Rupture } \\
(\mathbf{k N})\end{array}$ & $\begin{array}{c}\text { Area of } \\
\text { Cross-Section } \\
(\mathrm{mm} 2)\end{array}$ & $\begin{array}{c}\text { End } \\
\text { Shortening at } \\
\text { Peak }(\mathrm{mm})\end{array}$ & $\begin{array}{l}\text { Axial } \\
\text { Stress } \\
\text { (MPa) }\end{array}$ & $\begin{array}{l}\text { Density of } \\
\text { Specimen } \\
(\mathrm{kg} / \mathrm{m} 3)\end{array}$ & $\begin{array}{c}\text { Gain } \\
(\%)\end{array}$ & $\begin{array}{l}\text { Capacity } \\
\text { Overweight } \\
(\mathrm{kN} / \mathrm{kN})\end{array}$ & Mode of Failure \\
\hline Control & 152.4 & 2764.6 & 5.75 & 55.1 & 1147.3 & - & 12323 & Splitting of bamboo \\
\hline SCB-FRN-H & 210.8 & 8332.3 & 13.31 & 25.3 & 742.9 & 38.3 & 8695 & Buckling of specimen \\
\hline FCB-GRT-H & 226.1 & 8332.3 & 6.25 & 27.1 & 1670.2 & 48.4 & 4148 & Splitting of matrix \\
\hline FCB-EPX-I & 601.1 & 8332.3 & 13.82 & 72.1 & 1174.5 & 294.4 & 15681 & Compressive Crushing \\
\hline
\end{tabular}

Table 2. Specimen naming convention table.

\begin{tabular}{cccc}
\hline Specimen & Bamboo Shape & Matrix & Confinement \\
\hline Control & Full culm & - & - \\
\hline FCB-FRN-H & FCB & Furan-based & Hemp \\
\hline SCB-FRN-H & SCB & Furan-based & Hemp \\
\hline FCB-GRT-H & FCB & Grout & Hemp \\
\hline SCB-GRT-H & SCB & Grout & Hemp \\
\hline FCB-EPX-I & FCB & Epoxy & Improved \\
\hline
\end{tabular}

\subsection{Description of Materials and Specimens}

The composite cross-section chosen for this study is comprised of a cylindrical shape with a $100 \mathrm{~mm}$ diameter and $400 \mathrm{~mm}$ height. The composites cylinders are filled with Phyllostachys edulis or Moso culms before the matrix is poured in the cylindrical moulds. Moso bamboo is a commonly available and affordable bamboo species, which can be grown in most north temperate climates. Therefore, Moso with external diameters around $26 \mathrm{~mm}$ was selected for this study. The bamboo was harvested after three years. Following harvesting, the bamboo was dried in pyramid-shaped stacks outdoors for 6-8 weeks, depending on the season and weather conditions. No pesticides or chemicals were used during the growing or harvesting process. The dried bamboo was loaded onto containers and when it reached Shanghai port, the entire container was fumigated for up to 24 hours to exterminate insects. No other processing was conducted. The bamboo originated on managed bamboo plantations in the Chinese province of Anji County, Zhejiang. The compressive mechanical properties of the tested bamboo in this study were investigated using ISO 22157:2019 [29] standard code provisions. In total, ten compression tests were conducted according to the ISO standard code, which led to the average compressive strength of $56.1 \mathrm{MPa}$ (coefficient of variation $=0.034$ ) and average Young modulus equal to $9.76 \mathrm{GPa}$ (coefficient of variation $=0.117$ ). It should be mentioned that the scatter between the results of compression tests was negligible. The standard test experimental results correlate with the existing compressive test results in the literature including Dixon and Gibson [30] study on minuscule rectangular cubes cut from the body of bamboo culms leading to the compressive crushing strength values of $69.1 \mathrm{MPa}$. In addition, after testing more than 100 specimens, Chung and Yu [19] reported average values for compressive strength and modulus of elasticity in compression equal to $69 \mathrm{MPa}$ and 9.3 GPa, respectively, for Moso bamboo with 5-20\% moisture content. Lo et al. [31] reported 
a compressive strength equal to $56 \mathrm{MPa}$ for the aged Moso bamboo specimen with diameters around $45 \mathrm{~mm}$ in their tests.

A commercially available cementitious grout was used in this study. The chosen cementitious grout had a short preparation time. The 28-day concrete compressive strength on $50 \times 50 \times 50 \mathrm{~mm}$ concrete cubes achieved an average value of $58.7 \mathrm{MPa}$, which is close to the average compressive strength of $64.8 \mathrm{MPa}$ reached during the tests.

A bio-based furan resin is chosen as one of the matrix choices in this study. Furan resins are originally derived from hemicellulose, which is naturally found in waste products from the agricultural industries (e.g., bagasse, corncobs, flax shivers, cottonseed hulls and other residues) [32]. As one of the most stable bio-based thermosetting resins, furan resin is greatly resistant to biodegradation. However, this bio-based resin still offers a certain degree of environmental friendliness, since it is derived from renewable agricultural waste [33]. In addition, compared to petroleum-based resins, furan resins offer a remarkable improvement in the carbon storage potential when used as a matrix [34]. Furfuryl alcohol, the main raw material for the production of furan resins, has a global warming potential (in terms of kg-CO2-eq) of 1.3, compared to the unsaturated polyester resin at 7.5 and epoxy at 6.5 [34]. Chemically, furan resins include a group of polymeric liquids derived from furfuryl alcohol or compounds containing the basic furan ring structure that can be converted to resin by means of proper catalysts (acid or neutral catalysts) [32]. Furan resins are generally cured by catalysts, which trigger a polycondensation reaction, leading to a highly cross-linked poly (furfuryl alcohol) network which ultimately results in an infusible solid substance. The resulting resin is brittle but owns very strong mechanical properties and remarkable chemical resistance to acids, alkalis, solvents, and heat and fire exposure. Their mechanical properties can be significantly improved by the use of upgrading modifying copolymers and, suitable catalysts and controlled curing conditions. In this context, Biorez 141010 which is a Furfuryl Alcohol prepolymer resin developed by TransFurans Chemicals to be used with natural fibres was chosen for this study. Biorez 141010 is a self-crosslinking resin formulation, which is diluted in water (20-22 wt. \%) and exhibits a weight ratio of $78-80 \%$ furfuryl alcohol prepolymer. When combined with a natural fibre, BioRez attaches with the cell wall, producing a bio-derived composite that is durable, stiff and with enhanced dimensional stability [35]. In this study, the resin is cured in an oven at $80^{\circ} \mathrm{C}$ for 4 hours. The modules of storage of Biorez 141010 at room temperature was reported by the manufacturer equal to $3.22 \mathrm{GPa}$.

A low viscosity two-part epoxy resin was chosen to allow reaching the resin within hollow bamboo culms. The mechanical properties of the epoxy resin used as specified by the manufacturer are as follows: $3.12 \mathrm{GPa}$ flexural modulus, $123.4 \mathrm{MPa}$ flexural strength, 3.18 GPa tensile modulus, 72.4 MPa tensile strength, and 86.2 MPa compressive strength. The same epoxy resin was used to bond confinement wraps/jacket around the bamboo composite specimens.

The hemp fabric used for the confinement of bamboo composite columns was a woven bidirectional sheet. It was applied three times continuously around the bamboo composite specimens. The hemp fabric was epoxy-bonded to the column surface with the two-component epoxy. The tensile strength and modulus of elasticity of the fabric were $22 \mathrm{MPa}$ and $530 \mathrm{MPa}$, respectively. Hemp was the chosen natural fibre due to its sustainability, high tensile strength, and modulus of elasticity. With the purpose of simulating the effect of giant bamboo confinement for the 26-mm-bamboo culms in the composite sections, the FCB specimen with epoxy matrix was confined using a 100-mm-diameter PVC jacket with 3-mm-thick walls prior to application of three layers of hemp fabric. It should be noted that the thin-walled PVC jacket was chosen for this study only because the giant bamboo was not available at the time of this investigation (see Figure 1). The compressive strength of giant bamboo in the longitudinal direction matches that of the PVC jacket. In order to compensate for the weaker mechanical properties of giant bamboo to that of PVC jacket in the transverse direction, certain weak points through six longitudinal cuts were considered around the PVC jacket. Considering the successful results of the pilot tests that will be provided in the following sections, future tests will be conducted with giant bamboo confinement for the small-diameter of composite bamboo sections to form a $100 \%$ bio-based 
structural member. The modulus of elasticity and ultimate compressive strength of the PVC jacket were $7.91 \mathrm{GPa}$, and $58 \mathrm{MPa}$, respectively. It can be seen that the mechanical behaviour of PVC in compression matches that of Moso and Giant bamboo in compression.

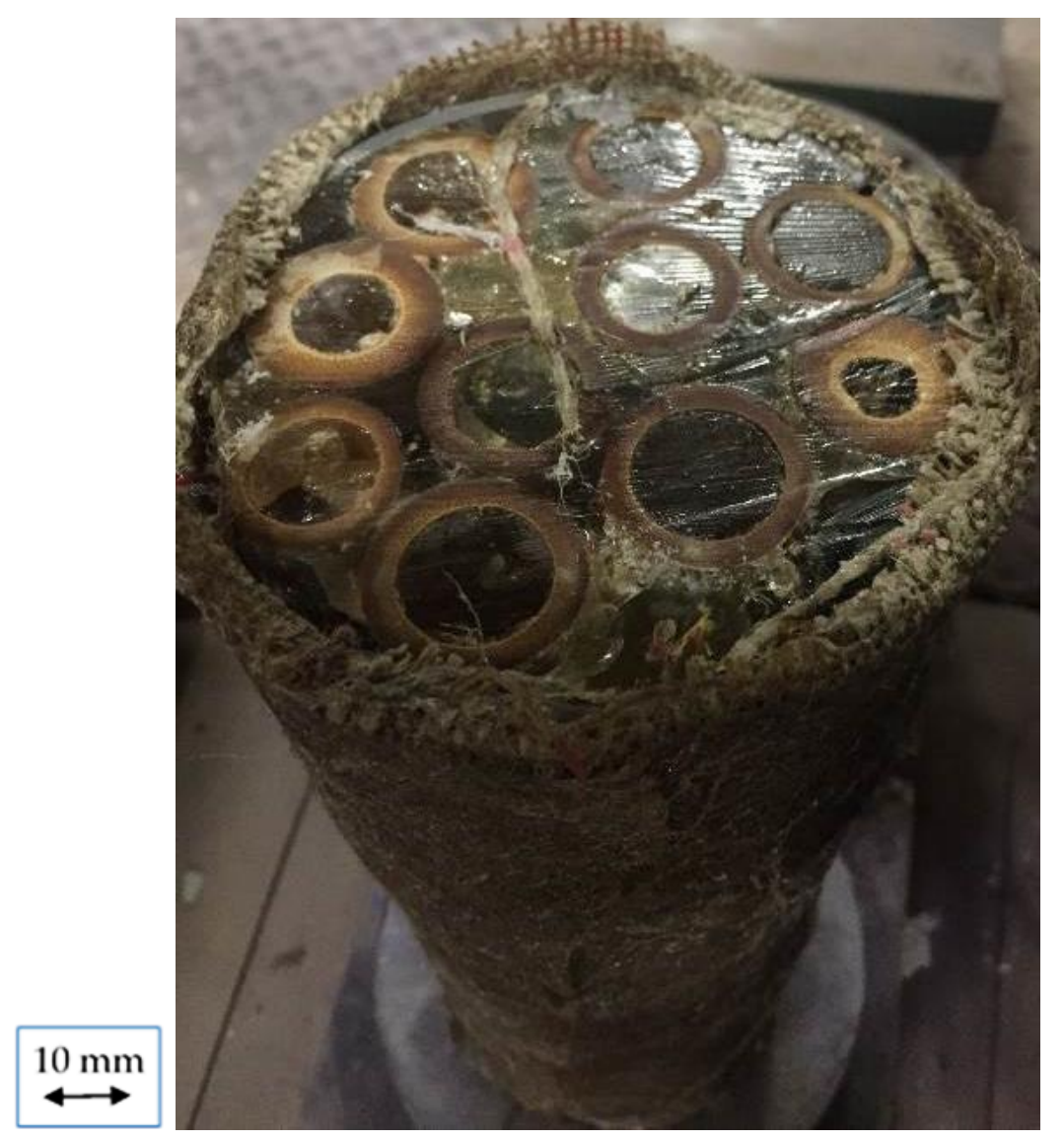

Figure 1. Cross-section of full culm bamboo composite (FCB)-epoxy matrix (EPX)-improved polyvinyl chloride (PVC) jacket (I) specimen before testing.

\subsection{Specimen Fabrication}

The bamboo culms were cut into $430 \mathrm{~mm}$ length to suit the height of the cast (i.e., $400 \mathrm{~mm}$ with a diameter of $103 \mathrm{~mm})$. The extra $30 \mathrm{~mm}$ compared to the specimen height $(400 \mathrm{~mm})$ was left with to hold the bamboos when the bamboo is dipped into the matrices. Meanwhile, the internal diaphragms at the nodes in the bamboo poles were drilled in order to create a tube for the resins/grout to pass through the interior of the bamboo poles and fill up the hollow sections. To manufacture SCB columns, a number of 430-mm-long bamboo culms were split to strips with $5 \mathrm{~mm}$ width to produce bamboo strips. In the composite specimens of the FCB series, nine bamboo culms were impregnated into their corresponding matrices and assembled into the cylinder cast to shape a single composite unit. The resins/grout were then poured gradually into the cast to fill the airspaces between the individual bamboo culm. Afterwards, the specimens were allowed to cure for the required duration based on the used type of matrix. The specimens were precisely cut to $400 \mathrm{~mm}$ height to guarantee a levelled surface. Subsequently, the epoxy-bonded hemp layers of confinement were applied around the specimens.

\subsection{Experimental Testing Methodology}

In this study, compressive tests were carried out on newly proposed FCB and SCB composites using an Instron universal testing machine. The compressive test is a fundamental test that signifies various strength parameters. Moreover, considering the slenderness of the specimens, the failure mode and strength can indicate the effectiveness of the confined bamboo-composite sections. A comparison 
between the axial compressive stress at the ultimate and compressive crushing strength of Moso bamboo can demonstrate the level of lateral support provided by the confinement against buckling. The six samples were positioned on machine loading plates on static load increment of $1 \mathrm{kN} / \mathrm{sec}$ and the load was recorded with a computerized data acquisition system. An extensive and carefully detailed measuring plot is chosen for the project. The longitudinal deformation of the specimens was measured using different Linear Variable Differential Transformers (LVDT) that record the relative displacement between the stiff plates of the machine. Much attention was paid to centralise the specimens on the plates prior to the testing before the axial loading was applied. All the specimens were instrumented with strain gauges to measure the axial and lateral deformations of the bamboo culms external surface at the different loading phases. The strain gauges were installed before the hemp fabric layers were applied (Figure 2).

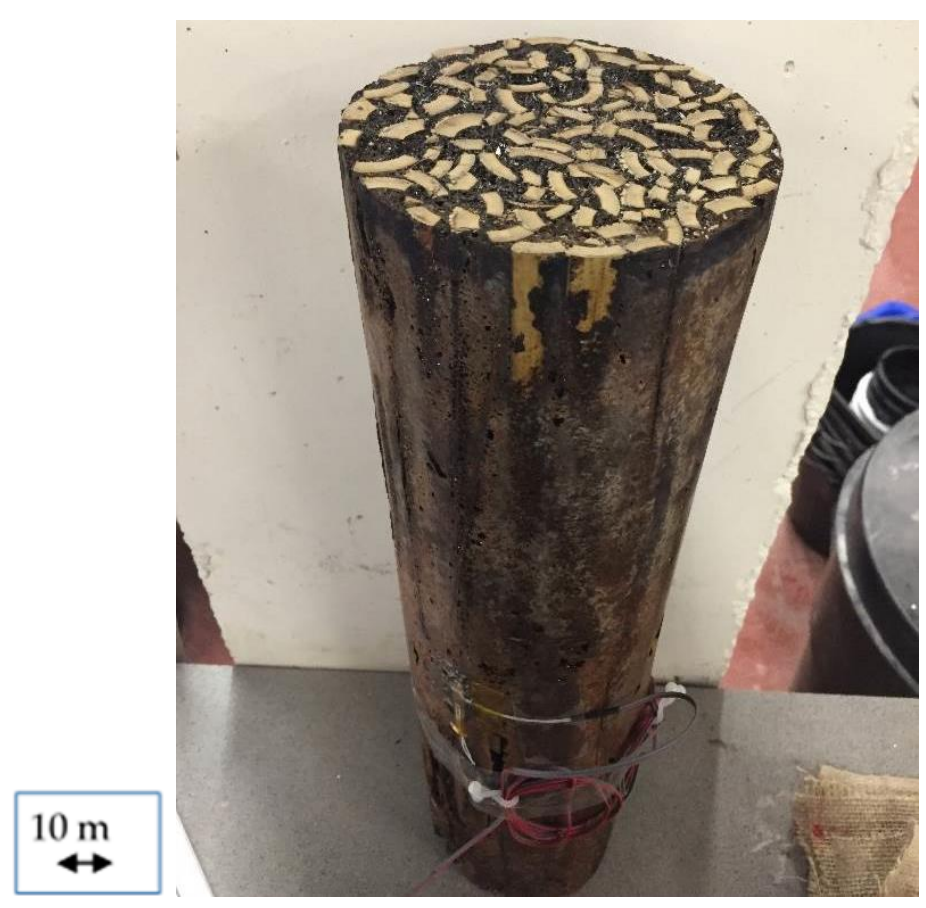

Figure 2. Specimen split culm bamboo composite (SCB)-furan-based matrix (FRN)-hemp fabric confinement $(\mathrm{H})$ before applying three layers of externally bonded hemp wrap.

\section{Results}

\subsection{Failure Mode}

Figures 3-8 show the failure modes of the tested specimens. In general, the failure mode of the specimens was mainly related to the composites' matrix and the confinement type of the columns. The failure of the control specimen was due to successive splitting of the bamboo culms of the bundle. The splitting failure started from the zones along the length of the culms where the sisal rope's confinement did not exist (see Figure 3).

The ultimate failure of the bundle took place due to successive failure of individual culms due to lack of interface and bonding matrix between the culms in the control specimen. The FCB-FRN-H specimen failed due to the buckling of the specimen when the applied axial load reached $223.3 \mathrm{kN}$, which was followed by local loss of hemp confinement at the top due to excessive bending. Although the specimen was noticeably bent during the loading phase, it was able to almost return to its aligned shape after unloading without losing its cross-sectional integrity (Figure 4). 


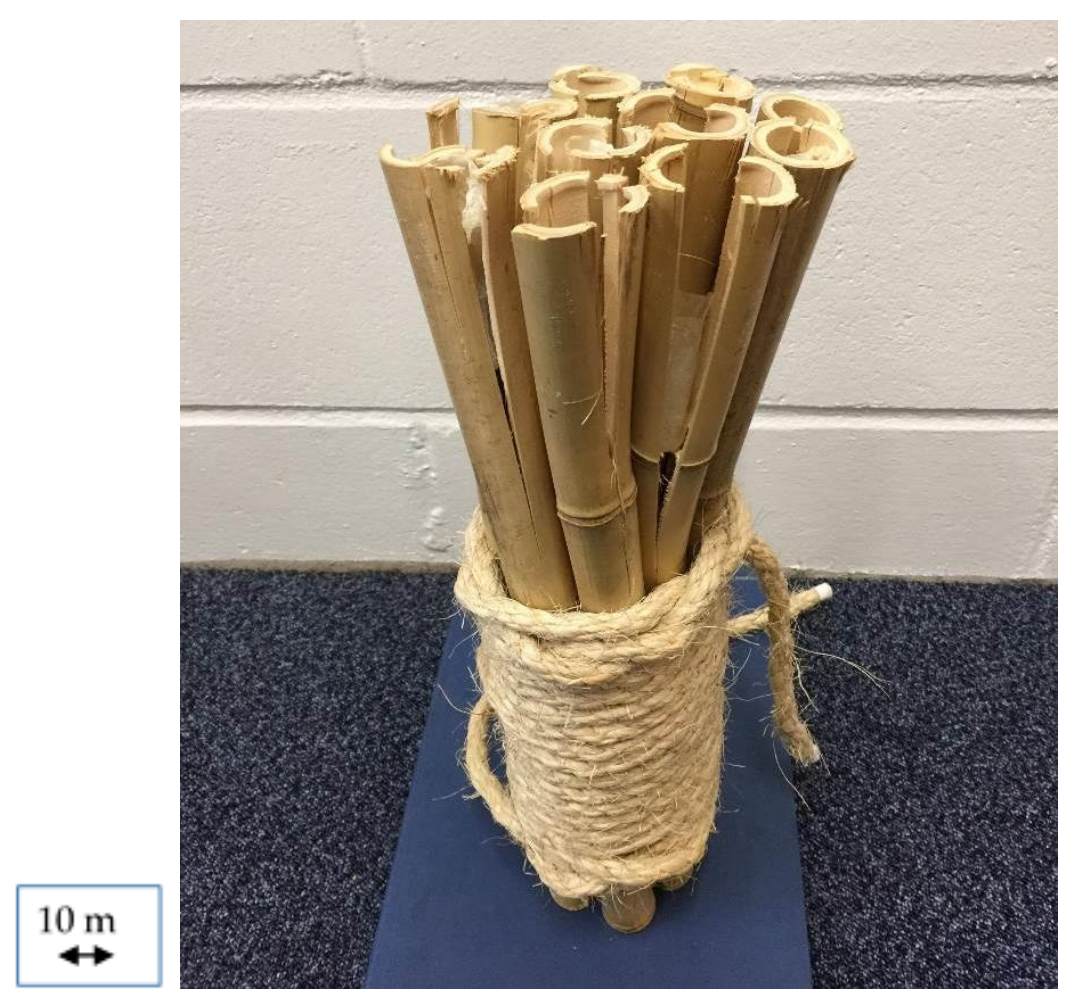

Figure 3. Failure mode of Control specimen.

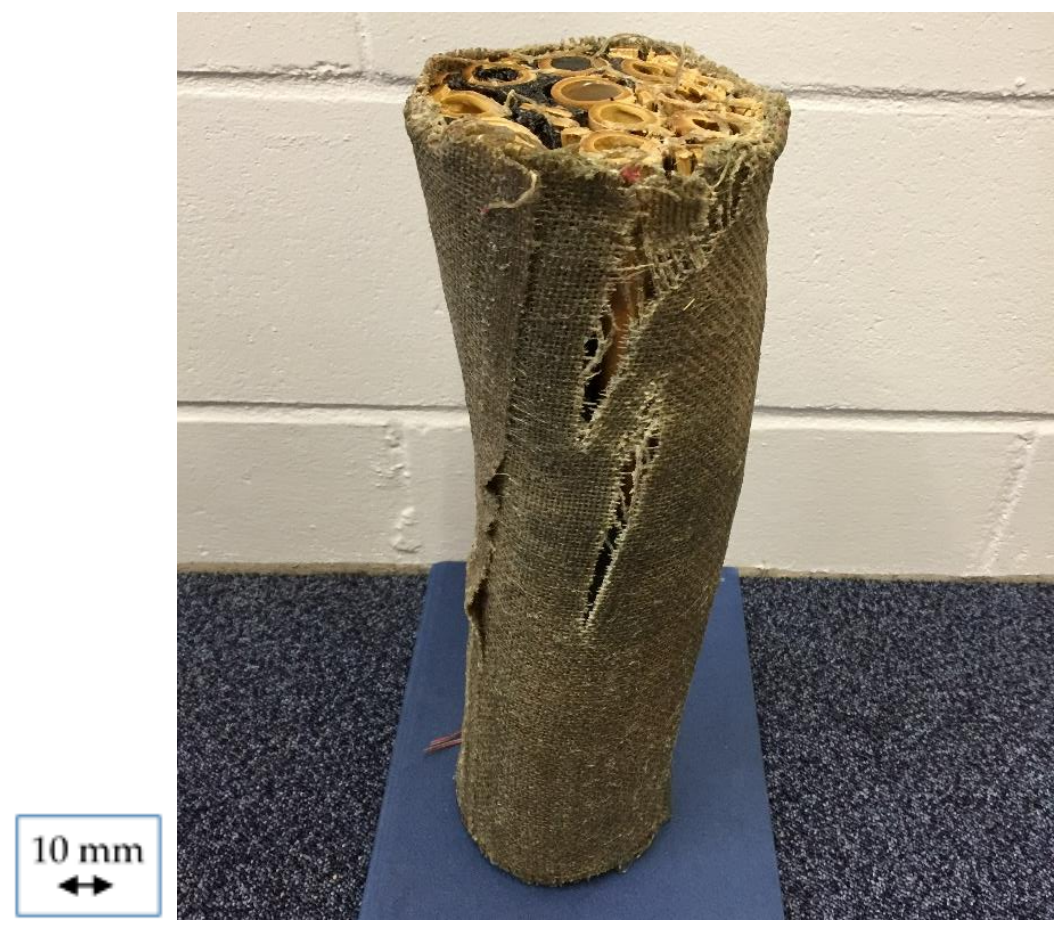

Figure 4. Failure mode of FCB-FRN-H specimen.

At the ultimate, the longitudinal axis of the FCB-FRN-H specimen experienced $34^{\circ}$ of rotation from the straight line at each end. The out of straightness was reduced to residual $4^{\circ}$ after the load was removed. Similarly, SCB-FRN-H specimen failed due to buckling of the specimen at $210.79 \mathrm{kN}$. Although the top part of the hemp fabric confinement was lost, the specimen was able to recover from its excessively bent shape with $34^{\circ}$ rotation of the longitudinal axis (Figure 5) to a residual $4^{\circ}$ out of 
straightness (Figure 6). The furan-based composite bamboo specimens confined with epoxy-bonded hemp showed excellent recovery characteristics after failure, which is not common among timber- or concrete-based structural sections after they enter their inelastic behaviour zone. Such characteristics can partially be affiliated to great recovery properties of bamboo. However, in FCB-FRN-H and SCB-FRN-H, the use of a furan-based matrix with epoxy-based confinement may have increased the recovery properties of the specimen. Czifrák et al. [36] reported a form of a shape memory resin through the development of a co-network of furan functionalized polyurethane and epoxy.

The FCB-GRT-H specimen failed due to the gradual opening of the hemp jacket confinement (from mid-height of the specimen) leading to grout matrix splitting which was followed by buckling of bamboo culms at a rather high load of $226.1 \mathrm{kN}$. Due to grout matrix splitting and the total opening of the hemp jacket, the deformed shaped of the specimen was irreversible after the load was removed (Figure 7). Similarly, the SCB-GRT-H specimen failed after the confinement of the hemp fabric was lost at a rather low failure of $143.3 \mathrm{kN}$, which can indicate poor composite action between bamboo strips and grout matrix. The initial opening of the hemp jacket was started from the top of the specimen (Figure 8).

On the other hand, the FCB-EPX-I specimen was able to sustain a significantly remarkable failure load of $601.1 \mathrm{kN}$ before experiencing a sudden rupture of the specimen due to compressive crushing of bamboo/epoxy (Figure 9).

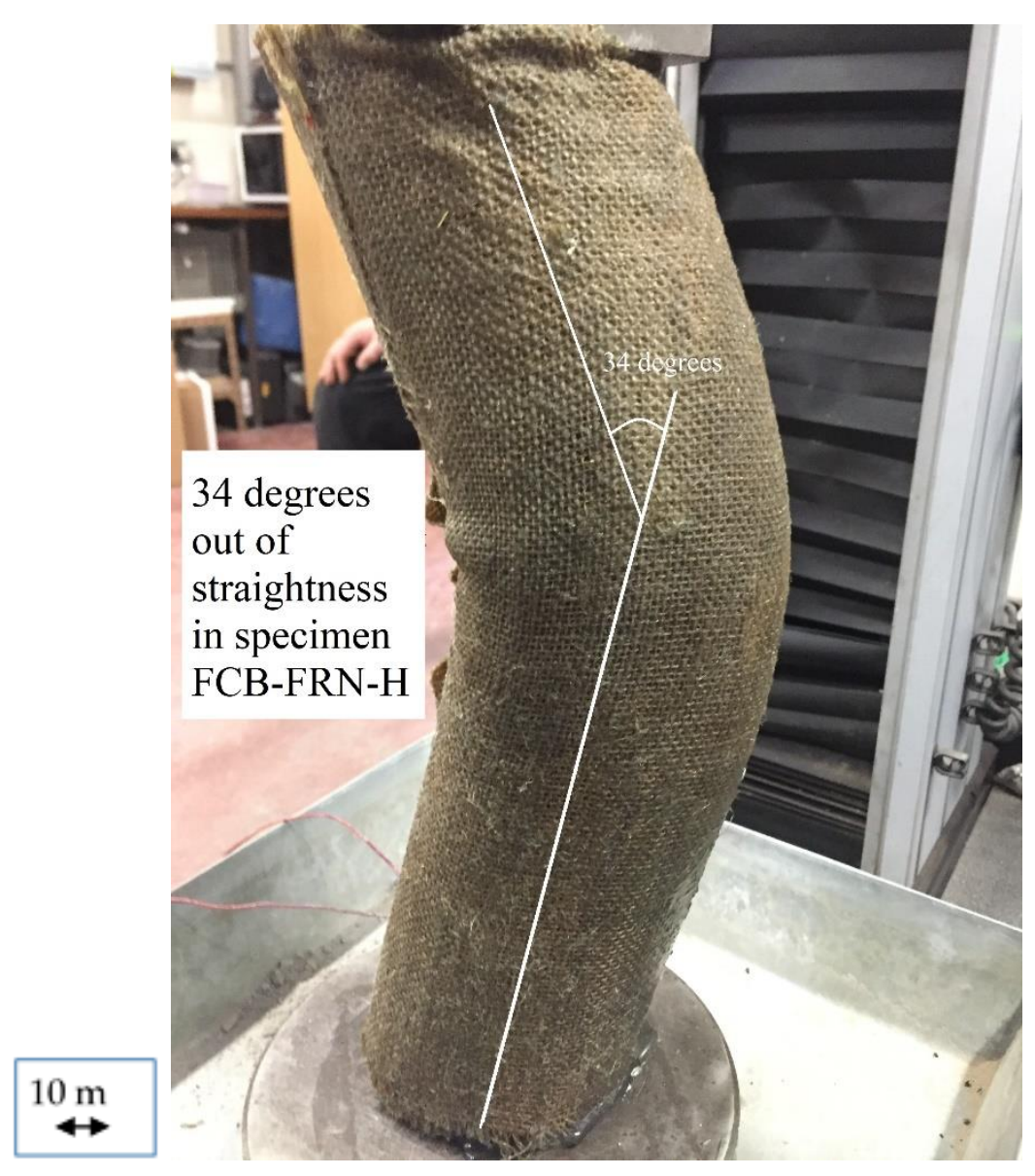

Figure 5. Specimen SCB-FRN-H at failure. 


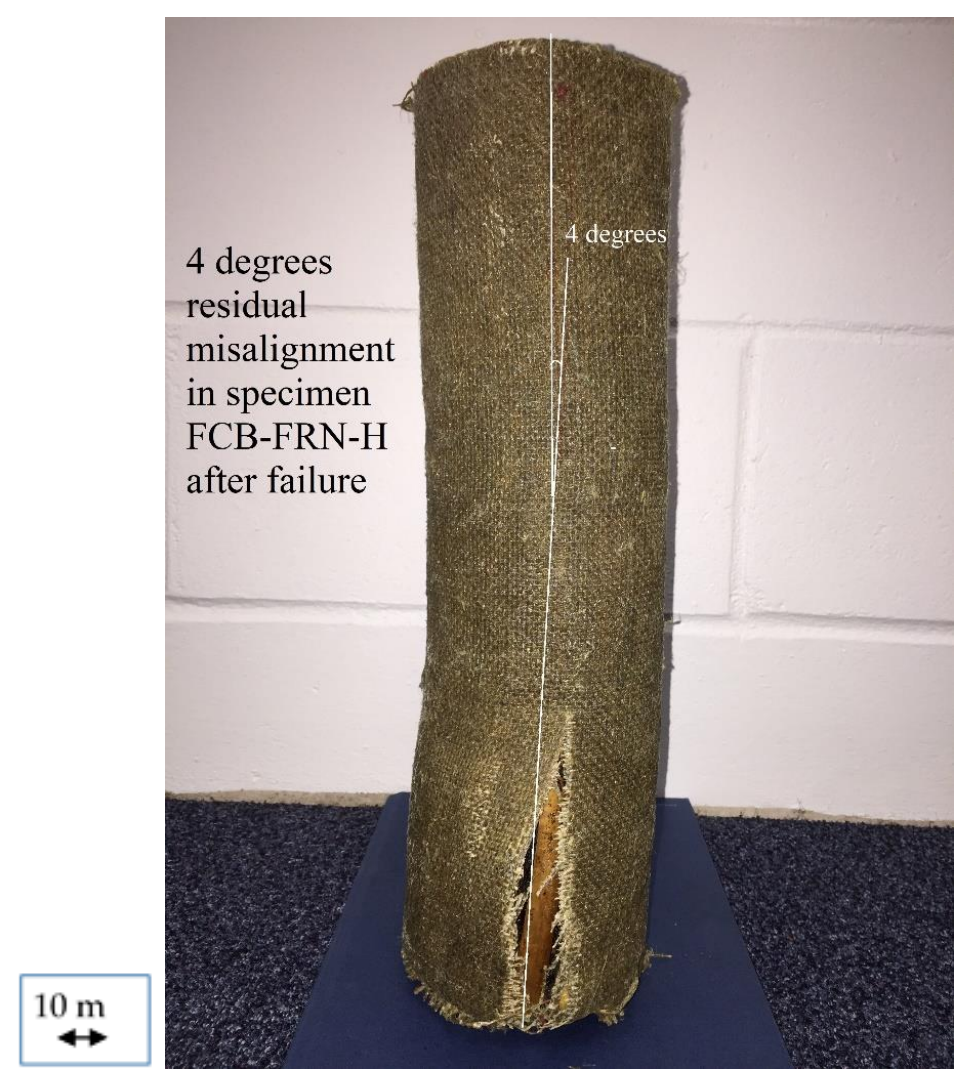

Figure 6. Specimen SCB-FRN-H after unloading.

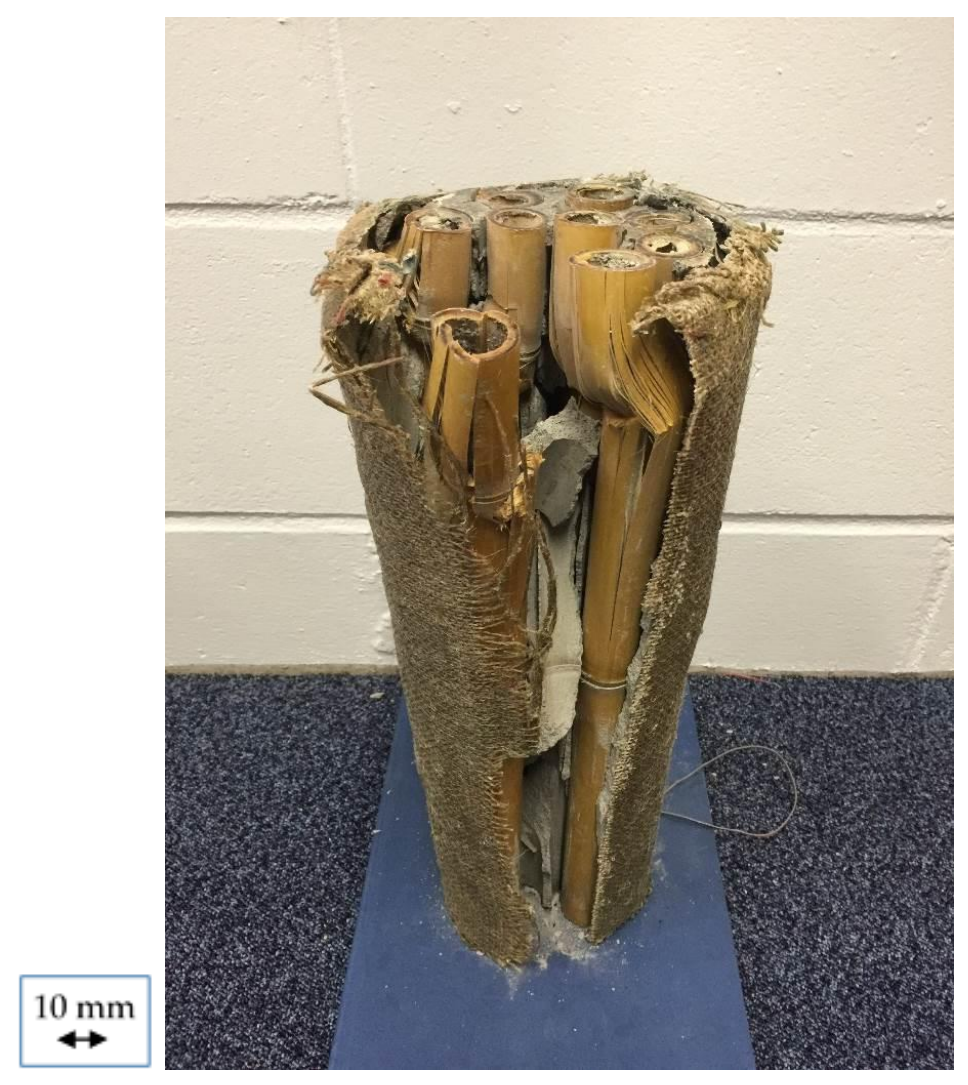

Figure 7. Failure mode of FCB- cementitious grout (GRT)-H specimen. 


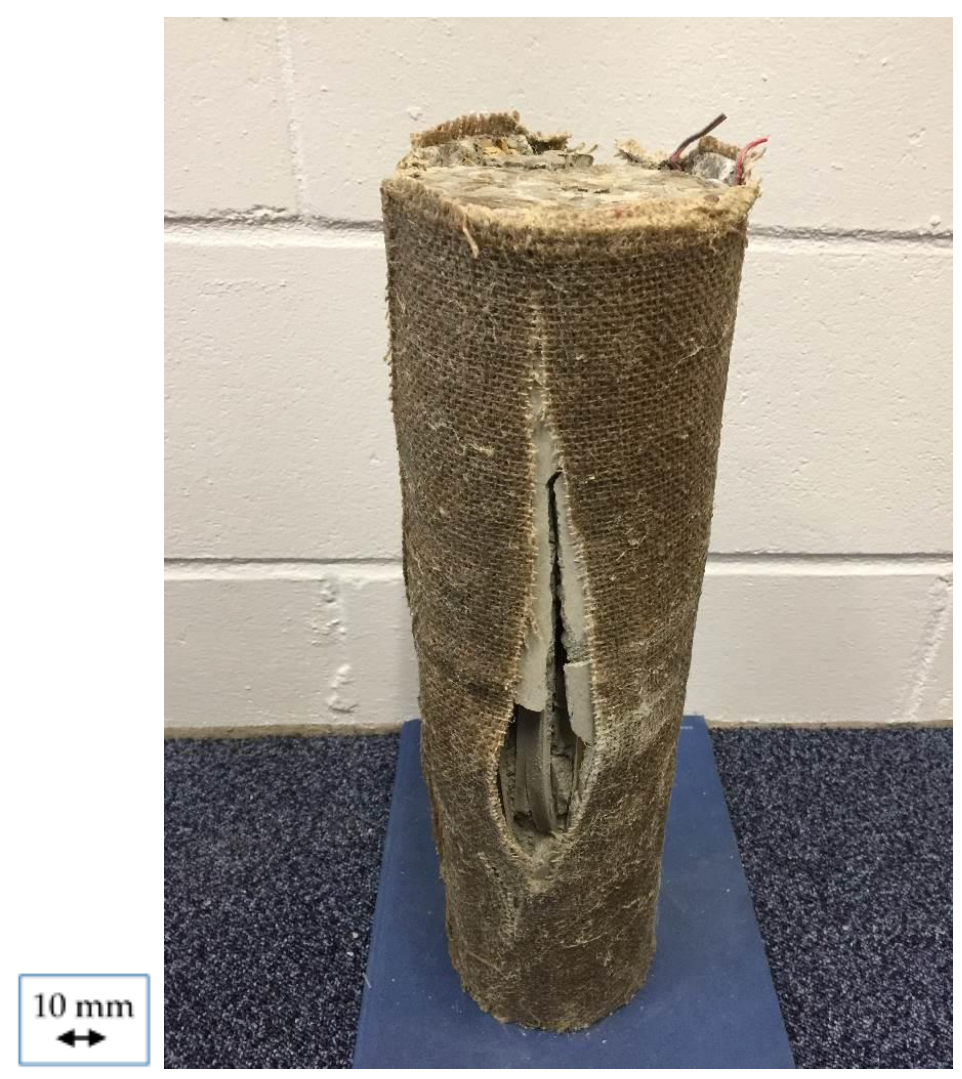

Figure 8. Failure mode of SCB-GRT-H specimen.

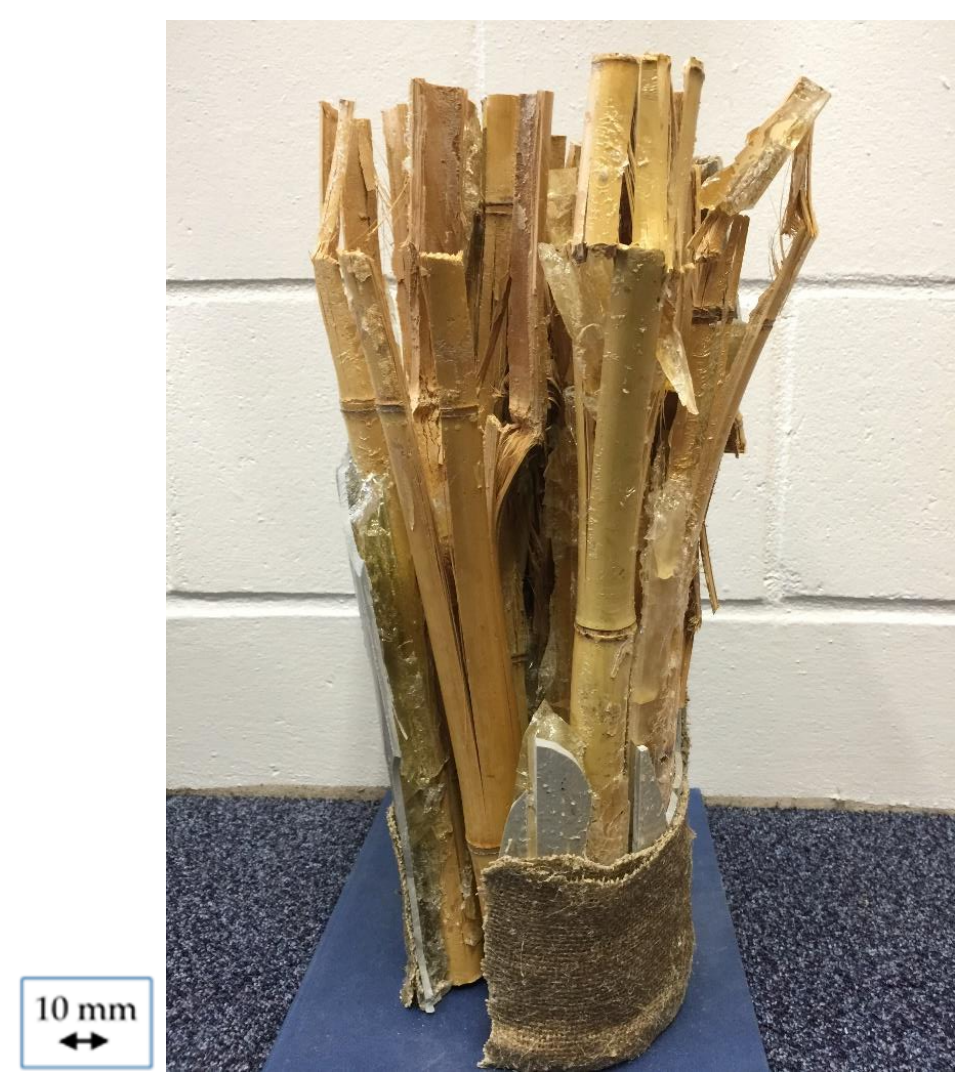

Figure 9. Failure mode of FCB-EXP-I specimen. 
Tables 1 and 2 summarize the experimental results obtained from the tests for all the specimens. The results are presented in terms of the axial loads attained at the peak, the axial compressive stress reached the peak, axial stiffness of the specimen, density of the specimens, the absorbed energy of the specimens, axial capacity overweight ratio, as well as axial capacity gain (hereafter called gain). While the later parameter will be discussed in this section, the rest of the calculated parameters in Tables 1 and 2 will be studied in the following sections. The gain is calculated as the ultimate load of each composite specimen subtracted by that of the control specimen overall divided by the control specimen failure load. The results show that the average gain due to the composite action between furan resin and bamboo in the FCB and SCB specimens is $42.4 \%$, compared to $48.4 \%$ gain for the FCB-GRT-H. However, composite action between bamboo strips and the cementitious grout did not take place effectively, leading to no gain in the axial capacity of the SCB-GRT-H specimen when compared with the control specimen. Conversely, the gain in the specimen with an epoxy matrix and improved confinement was the remarkable value of $294.4 \%$. In general, the gain values of the newly proposed composite sections show that most of the proposed composite sections (except for SCB-GRT-H) were able to provide significant improvements to the axial load carrying capacity of the specimen made of raw bamboo.

\subsection{Displacement Response}

Figure 10 shows the curves representing the load versus the end-shortening of the FCB and SCB columns and the control specimen. The control specimen (bamboo bundle) reached a maximum load of $152.4 \mathrm{kN}$ at the peak before it failed in a rather brittle manner. The recorded shortening of the control specimen at the peak is $5.8 \mathrm{~mm}$ which is the smallest compared to that of all tested composite sections. The composite specimen with the minimum displacement at peak among other composite sections, and after the control specimen, is the FCB-GRT-H with $6.3 \mathrm{~mm}$ shortening. The specimen reached the maximum load at the displacement of $4.7 \mathrm{~mm}$ and was able to sustain the load until the displacement reached $6.3 \mathrm{~mm}$ by representing a certain level of ductility in the behaviour of the specimen. It should be mentioned that after the specimen reached its maximum load at a displacement of $4.7 \mathrm{~mm}$, a slight drop was observed on the load-displacement curve of FCB-GRT-H specimen, which was followed by a hardening stage. This behaviour can be attributed to the local loss of jacket confinement at the mid-height of the specimen which was followed by the stress redistribution on the undamaged confinement parts of the hemp jacket followed by crushing of the grout matrix which increased the matrix materials density and led to improved mechanical property. Hence, a slight hardening stage was observed on the load-displacement curve. This occurred when the load reached $225.1 \mathrm{kN}$ at a displacement of $4.7 \mathrm{~mm}$ and dropped to $220.2 \mathrm{kN}$ with $5.20 \mathrm{~mm}$ displacement before it increases to $225.8 \mathrm{kN}$ with $6.25 \mathrm{~mm}$ displacement. For specimen FCB-FRN-H, the displacement at the peak was equal to $8.0 \mathrm{~mm}$ with a sustained load of $223.3 \mathrm{kN}$. The SCB-FRN-H and SCB-GRT-H specimens failed in the most ductile manner among other specimens. This can be observed from the noticeable plateau in the load-displacement curves of the SCB-FRN-H and SCB-GRT-H specimens. In fact, the two SCB specimens behaved similarly to each other in the pre-peak and post-peak zones of the curve with different peak loads. This could be attributed to the similarity of the bamboo strip distribution in the cross-section. The FCB-EPX-I specimen failed in a sudden and brittle manner at a significantly greater load $(601.1 \mathrm{kN})$ compared to that of other specimens with displacement equal to $14.1 \mathrm{~mm}$. The sudden manner of the FCB-EPX-I specimen failure resulted in a load-displacement curve without an offloading segment. Meanwhile, Figure 10 reveals that FCB-GRT-H and FCB-EPX-P specimens showed a greater overall stiffness compared to the rest of the columns. The maximum loads at failure and the maximum displacements are provided in Table 1. It can be seen that the composite action through the usage of different matrices for bamboo fibres and proper confinement greatly enhanced the overall behaviour of the columns. In this study, the composite specimens experienced greater loads at failure, greater deflection at the peak, and in most specimens a more ductile behaviour than those of the control specimen (Figure 10). 


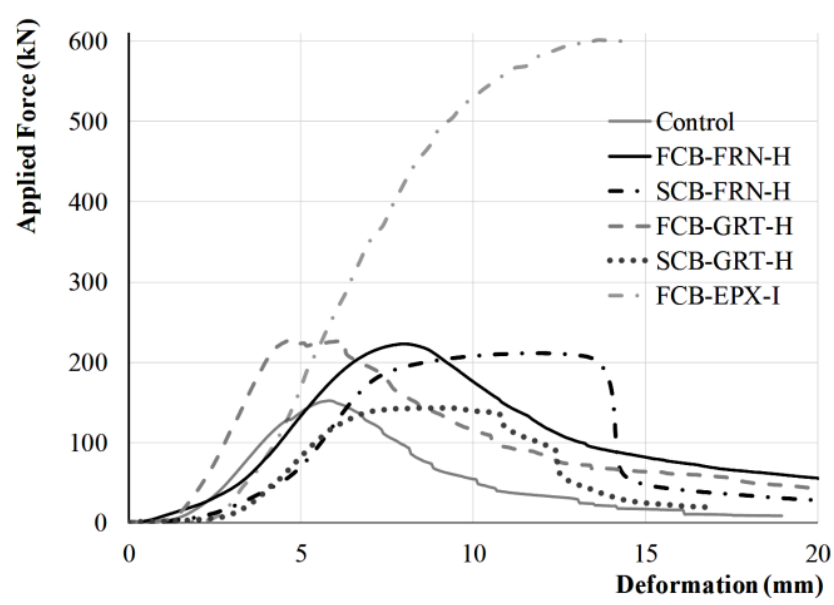

Figure 10. Load versus end-shortening of tested small-scale columns.

\subsection{Strain Response}

Longitudinal strain-Figure 11 shows the curves representing the load versus the longitudinal strain of bamboo for all the composite specimens and the control specimen. The longitudinal strain started to pick up only after the applied load reached $53 \mathrm{kN}$. This is mainly due to the lack of composite action in the bamboo bundle that leads to the isolated distribution of axial stresses in the cross-section between different culms. The divided stress distribution in the initial phase is due to slight differences in the length of each bamboo culm in the bundle. As the load increases, all the specimens touch the loading plate and start contributing to the axial resistance of the column. The strain reading of the control specimen reaches a softening stage after the initial and rather stiffer stage. The softening can correspond to the cracking of the bamboo culms, which continues until the specimen fails due to splitting of the bamboo culms. The longitudinal strain reading at peak for the control specimen was a rather low strain of 0.0029 . As it can be seen in Figure 11, the curves corresponded to the two SCB specimens follow a similar trend. After a short initial phase that the strain started increasing with a steep slope for both SCB specimens, the rate of the strain increase diminishes to a shallower slope and with a linear behaviour until it reaches the peak load. Meanwhile, the SCB-GRT-H experiences a strain setback at the strain level of 0.0035 , which is due to a crack opening in the substrate grout layer due to local damage to hemp jacket at the top of the specimen. Afterwards, the strain readings started to pick up after confinement stress redistribution takes place to the undamaged parts of the hemp jacket. Such behaviour also was observed in the other specimen with a cementitious-based matrix. The strain readings in the FCB-GRT-H specimen started with a similar steep slope as that of the SCB-GRT-H specimen. However, the FCB-GRT-H continued the initial stiff behaviour until the late stages of the loading (applied force of $215.1 \mathrm{kN}$ ) at the strain of 0.0017 when a strain setback took place. The hardening of the FCB-GRT-H specimen took place at this stage with a significantly shallow slope, which resulted in a plateau that was observed earlier in the load-displacement curve and can also be observed here. The substantial difference between the FCB-GRT-H and SCB-GRT-H specimens' stiffness can be attributed to a significant difference in the quality of the composite action between the cementitious matrix and the two different bamboo fibre forms. From the behaviour of the two specimens one can conclude that the grout matrix and bamboo culms in the FCB-GRT-H specimen worked in a harmonious manner, such action was not observed in the SCB-GRT-H specimen between the grout matrix and bamboo strips. The SCB-GRT-H specimen behaved in a much softer manner compared to the behaviour of the FCB-GRT-H specimen. Even though both specimens were benefiting from similar grout matrix and bamboo material. The FCB-FRN-H load versus longitudinal strain behaviour constituted three separate stages. In the first phase, as the load increased the strain increased with the lowest rate among all other specimens. In the second phase, the rate of strain increments started to increase until it reaches a third stage, which is considered a softening stage when 
compared to the second stage of the loading. This stage started at the applied load of $180 \mathrm{kN}$ and can be attributed to the cracking that took place in the bamboo material which led to a softer behaviour of the section until it fails at a load of $223.3 \mathrm{kN}$. The vertical segment in the strain curves indicates that the strain gauge readings were lost at that load stage due to damage to the strain gauge after the excessive deformations experienced in the strain gauge substrate. The load versus strain reading of the FCB-EPX-I specimen was not available due to technical difficulties. However, the maximum measured longitudinal strain on the external bamboo surface was equal to 0.0058 at ultimate.

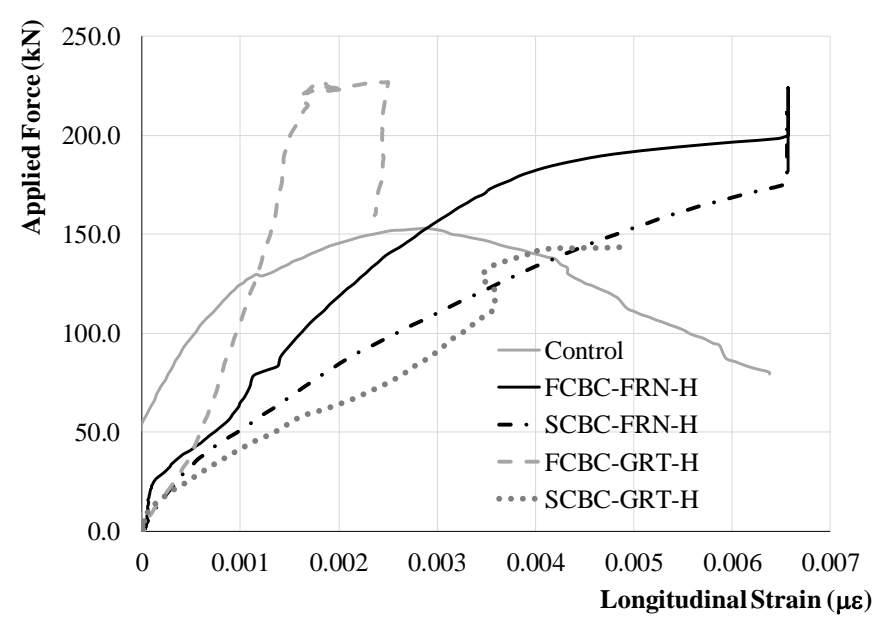

Figure 11. Load versus measured longitudinal compressive strain on an external bamboo for all tested specimens.

Lateral strain-Figure 12 represents the curves of the applied load versus the lateral strains on the surface of an external bamboo component in the composite cross-section for furan- and grout-based specimens. Meanwhile, Figure 12 reveals the entirely different behaviour of the grout-based specimens in terms of lateral stiffness with one another that can be corresponded to the poor composite action between the grout matrix and bamboo strips which puts too much lateral strain in the bamboo strips. This leads to a significantly greater rate of lateral strain increase in the SCB-GRT-H specimen compared to that of the FCB-GRT-H specimen. When the lateral strain increases to 0.0036 , local damage to the hemp confinement takes place before the confinement is lost completely at the ultimate. The general behaviour of the FCB-GRT-H specimen is similar to that of the SCB-GRT-H, except for the lateral stiffness attributes. The stronger composite action between the bamboo culms and the cementitious matrix leads to the smaller lateral strain rate increase, which puts less pressure on the hemp confinement. Nevertheless, the confinement in the FCB-GRT-H starts to weaken at a rather high load of $223.9 \mathrm{kN}$ and rather low lateral bamboo strain of 0.0022. At this stage, the hemp jacket starts to unfold at the mid-height of the specimen. This leads to the sudden increase in the lateral strain in the bamboo surface, which reaches 0.0038 at the ultimate when the confinement is completely lost. Remarkably, compressive lateral strain in the FCB-FRN-H specimen was developed in the initial stages of the loading under longitudinal compressive stresses, which indicates the compatibility of the furan matrix and the bamboo culms with the hemp confinement. The hemp confinement was able to provide immediate confinement to the specimen to provide lateral compressive strain to the bamboo against the course of loading. As the compressive axial loading increases, Poisson's effect takes control of the lateral strain in the bamboo with an increased rate of tensile lateral strain in bamboo, similar to that of other specimens. The SCB-FRN-H specimen gains lateral strain with a greater rate than that of the FCB-FRN-H, which indicates greater confinement and composite action in the FCB-FRN-H specimen compared to that of the SCB-FRN-H specimen. 


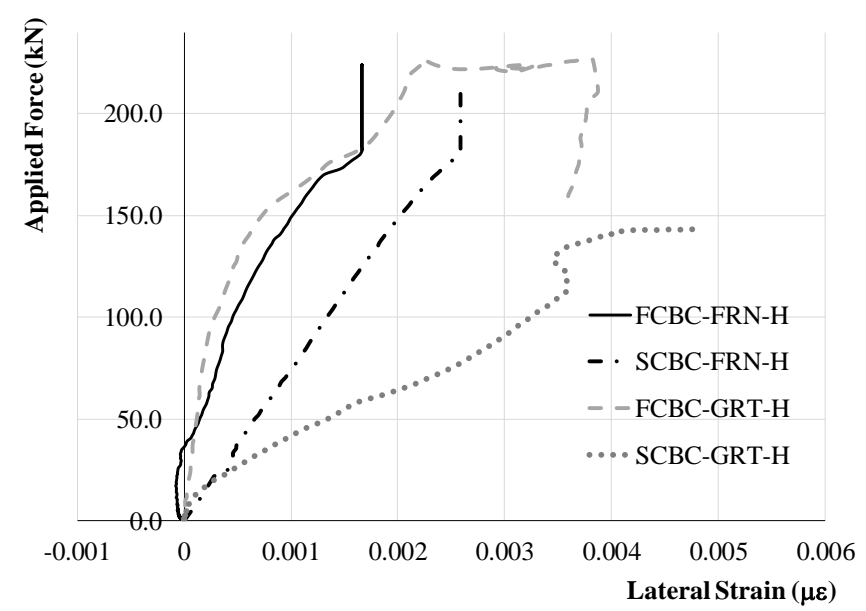

Figure 12. Load versus measured lateral tensile strain on an external bamboo for all tested specimens.

\section{Discussions}

In this section, based on the experimental results provided in the previous section, different compressive mechanical properties of the studied specimens are investigated. Considering the unprecedented nature of the proposed bamboo-composite columns, parameters such as axial ductility, axial stiffness, and absorbed energy of the columns are required to be investigated before the members can be used in construction as load-bearing members. Meanwhile, engineers in practice should be able to predict the compressive capacity of the novel members to be able to use them in construction projects. To this end, design equations are provided in this section to predict the axial capacity of the member with reasonable accuracy.

\subsection{Axial Ductility and Stiffness}

Ductility index $(D I)$ is defined as the ratio between displacement at a load of $0.85 P_{\max }$ post-peak and the displacement at peak load, whereas the specified ductility index (SDI) is proposed as DI per unit mass. The SCB-FRN-H represented the greatest amount of ductility between the tested specimens in terms of $D I$ with ductility index equal to 1.58 . Both grout-based specimens showed a ductile behaviour considering their DI equal to 1.47 and 1.46 for FCB-GRT-H and SCB-GRT-H specimens, respectively. The FCB-EPX-I did not represent ductile behaviour and failed in a brittle manner. Meanwhile, the specimen with the greatest SDI was the control specimen considering its lighter weight compared to other specimens $(S D I=0.971 / \mathrm{kg})$. Among the composite specimens, the SCB-FRN-H reached the greatest SDI equal to $0.641 / \mathrm{kg}$, which was due to its ductile behaviour and rather lightweight. The axial stiffness of the columns is calculated based on the secant stiffness of the specimens considering that the secant line intersects the load-displacement curves at the point where the load reaches $0.75 P_{\max }$ at the pre-peak stage (Tao et al. 2007). Among the tested specimens, the FCB-GRT-H was the specimen, which represented the greatest axial stiffness with $K_{i}$ (axial stiffness) of $47.1 \mathrm{kN} / \mathrm{mm}$. This constitutes a 73\% increase in the axial stiffness of the FCB-GRT-H specimen over the control column. In addition, FCB-EPX-I specimen was among the stiffer specimens with $K_{i}$ equal to $30.3 \mathrm{kN} / \mathrm{mm}$. On the contrary, the specimen SCB-GRT-H showed the least amount of axial stiffness with $K_{i}$ of $19.2 \mathrm{kN} / \mathrm{mm}$, which corresponded to $29 \%$ decrease in the axial ductility when compared to the control specimen. The ductility indices and the axial stiffness are provided in Table 3. 
Table 3. Calculated ductility, stiffness, and energy absorption parameters.

\begin{tabular}{cccccc}
\hline Specimen & $\begin{array}{c}\text { Ductility } \\
\text { Index } \\
\mathbf{m m} / \mathbf{m m}\end{array}$ & $\begin{array}{c}\text { Specified } \\
\text { Ductility } \\
\mathbf{1 / k g}\end{array}$ & $\begin{array}{c}\text { Axial } \\
\text { Stiffness } \\
\mathbf{k N / \mathbf { m m }}\end{array}$ & $\begin{array}{c}\text { Absorbed } \\
\text { Energy } \\
\mathbf{k N} \cdot \mathbf{m m}\end{array}$ & $\begin{array}{c}\text { Specified Absorbed } \\
\text { Energy } \\
\mathbf{k N} \cdot \mathbf{m m} / \mathbf{g r}\end{array}$ \\
\hline Control & 1.22 & 0.97 & 27.2 & 986.2 & 0.78 \\
\hline FCB-FRN-H & 1.26 & 0.40 & 29.5 & 2811.8 & 0.90 \\
\hline SCB-FRN-H & 1.58 & 0.64 & 23.9 & 2096.6 & 0.85 \\
\hline FCB-GRT-H & 1.47 & 0.26 & 47.1 & 2298.4 & 0.41 \\
\hline SCB-GRT-H & 1.46 & 0.21 & 19.2 & 1177.1 & 0.17 \\
\hline FCB-EPX-I & 0 & 0 & 30.3 & 4634.0 & 1.18 \\
\hline
\end{tabular}

\subsection{Absorbed Energy}

In order to build earthquake-resisting structures, it is important to use building materials that resist the seismic loads without failure by withstanding/absorbing the seismic energy within the materials linear or non-linear range. Toughness is defined as the energy absorption capacity of materials, which is commonly defined as the area under load-displacement (or axial stress-strain) curve for a compressive test. The absorbed energy by volume $(A E)$, in this article, is calculated based on the load-displacement curve with a unit of $\mathrm{kN} \cdot \mathrm{mm}$ or J. The specified absorbed energy $(S A E)$, however, is calculated through dividing the $A E$ by the mass of the specimens. In this regard, the specimen with the greatest amount of endured energy was the FCB-EPX-I with $A E$ equal to $4634.0 \mathrm{~J}$. The specimen FCB-FRN-H was the second-best specimens in terms of energy absorption with $A E$ of $2811.8 \mathrm{~J}$. Meanwhile, the specimen with the least amount of energy absorption was the control specimen with $A E$ equal to $986.2 \mathrm{~J}$. Similarly, the two specimens with the greatest $S A E$ were FCB-EPX-H and FCB-FRN-H specimens with $1.18 \mathrm{~J} / \mathrm{gr}$ and $0.90 \mathrm{~J} / \mathrm{gr}$, respectively. However, considering the rather heavyweight of the grout-based specimens, they represented the least amount of $S A E$ among all specimens, i.e., $0.41 \mathrm{~J} / \mathrm{gr}$ and $0.17 \mathrm{~J} / \mathrm{gr}$ for FCB-GRT-H and SCB-GRT-H, correspondingly. The energy absorption indexes are provided in Table 3.

\subsection{Prediction of the Axial Capacity}

In order to predict the behaviour of the composite sections, the theoretical axial load $\left(P_{\text {theory }}\right)$ is calculated by a superposition of the axial stress of the i-th component at ultimate multiplied by the cross-sectional area of the i-th component as follows:

$$
P_{\text {theory }}=\sum_{i=1}^{n} \sigma_{i} A_{i}
$$

It is important to note that between the matrix and the fibre, in a two-component composite, the first component to reach its ultimate strain fails which will generally lead to the failure of the specimen. Therefore, the axial strength of the first component to fail can be used in Equation (1). Due to compatibility, the other component should have experienced the same amount of strain at ultimate, which can then be used to calculate its stress at the ultimate in Equation (1). Therefore, for the two-component (matrix and fibre) composite specimens, the following equation will be used to predicate their capacity:

$$
P_{\text {theory }}=\left(\sigma_{m} A_{m}+\sigma_{f} A_{f}\right)
$$

where $\sigma_{m}, A_{m}, \sigma_{f}$, and $A_{f}$ are the stress at the ultimate in the matrix, area of cross-section of the matrix, stress at the ultimate in fibre, and area of cross-section of fibre, respectively. According to the experiment, the control specimen failed under $152.4 \mathrm{kN}$ of force which resulted in compressive strength of $55.1 \mathrm{MPa}$ at the ultimate for the tested Moso bamboo of the control specimen. This result shows a reasonable correlation with the experimental results on single bamboo culms according to ISO 
22157:2019. Considering the results of the standard tests in this study on bamboo culms, the theoretical mechanical properties of Moso bamboo will be considered equal to 56.1 MPa and 9.76 GPa for compressive strength and modulus of elasticity, respectively. This leads to an ultimate compressive strain of 0.0052 for Moso bamboo in this study. For FCB-GRT-H specimen, it is expected that the grout (the matrix) fail first considering a smaller maximum compressive strain of grout $(0.0035)$ than that of Moso bamboo. This means grout reaches its ultimate strain, hence the compressive strength of the grout can be used as $\sigma_{m}$ in Equation (2). Meanwhile, in Equation (2), the stress in bamboo, in FCB-GRT-H for example, can be calculated based on the compressive strain of 0.0035 . It should be mentioned that after the failure, it was observed that the hollow areas inside bamboo culms were not fully filled with grout. Therefore, the area inside the bamboo culms was not considered in the calculation of $A_{m}$ for this specimen. For the SCB-GRT-H specimen, as it was mentioned earlier, the composite action between the bamboo strips and grout did not take place properly. Therefore, the two components of the composite section were acting separately. In the calculation of the axial capacity, the contribution of the grout matrix was neglected since the grout component failed to act as a separate load-carrying body due to the distributed presence of bamboo strips in the grout cross-section. Hence, the capacity of the SCB-GRT-H specimen is calculated based on the strength of bamboo strips multiplied by their area of cross-section. For the furan-based specimens, it is expected that bamboo fails first due to the smaller compressive longitudinal strain of bamboo compared to that of furan resin. Thus, bamboo's full strength should be used in the Equation (2). Based on compatibility, the strain in the furan should be limited to the maximum strain of bamboo in compression, i.e., 0.0052 in this study. Therefore, the stress in furan resin for both furan-based specimens can be calculated through multiplying 0.0052 by $3.22 \mathrm{GPa}$ (the modulus of elasticity of the cured resin at room temperature is $3.22 \mathrm{GPa}$ ). It should be noted that, unlike the FCB-GRT-H specimen, the hollow area of bamboo culms was filled with furan resin due to expansive behaviour of the resin during curing. For FCB-EPX-I, three components contributed to the axial capacity of the specimen: bamboo culms, epoxy and PVC jacket. To this end, for specimen FCB-EPX-I, the Equation (2) should be revised to Equation (3) which includes an extra term regarding the contribution of the jacket to the axial capacity of the specimen. According to compressive tests on epoxy specimens by Yekani Fard [37], the measured compressive strain of epoxy at peak load is 0.005 , whereas the strain of epoxy at ultimate is 0.03 . This means the stress-strain curve of epoxy in compression is not a linear curve until failure. A softening stage starting strains at 0.005 exists when epoxy is under compressive load (e.g., Yekani Fard [37]). Meanwhile, the compressive tests by Ogendal [38] on PVC specimens shows that the strain at peak and ultimate are similar values (linear stress-strain behaviour in PVC till failure). Therefore, the used PVC strain at ultimate can be calculated equal to 0.0073 from the given properties of the used PVC jacket. By comparing the ultimate strain of the three components, one can conclude that the first component to break is bamboo at a strain of 0.0052 . The strain gauges on external bamboo mounted on FCB-EXP-I measured 0.0058 strain on the external bamboo surface at the ultimate, which indicates that bamboo was strained to its compressive limits prior to failure. Therefore, the full compressive strength of bamboo can be used in Equation (3) as $\sigma_{f}$. Meanwhile, at a strain of 0.0052 , epoxy has only slightly passed its strength of $86.2 \mathrm{MPa}$ and to some extent entered its softening stage. Based on the studies by Yekani Fard [37], the strength of epoxy at the compressive strain of 0.0052 can be approximated equal to $86.0 \mathrm{MPa}$ (rather than its strength at the pick of $86.2 \mathrm{MPa}$ ). In addition, considering the linear behaviour of the PVC material until failure, the stress in a PVC jacket can be calculated using a strain of 0.0052 and used in Equation (3) as the stress of jacket $\sigma_{j}$ to calculate the FCB-EPX-I specimen $P_{\text {theory }}$ as follows:

$$
P_{\text {theory }}=\left(\sigma_{m} A_{m}+\sigma_{f} A_{f}+\sigma_{j} A_{j}\right)
$$

It should be noted that due to fluidity of the epoxy resin prior to curing, the hollow area of bamboo culms was filled with epoxy. Therefore, the hollow area of bamboo should be considered in the calculation of $A_{m}$. The calculated results of $P_{\text {theory }}$ are provided in Table 4 with notable proximity to the experimental failure loads, i.e., $9 \%$ average error. 
Table 4. Comparison of predicted and experimental axial capacity.

\begin{tabular}{ccccccc}
\hline Specimen & $\begin{array}{c}\text { Bamboo } \\
\text { Volume } \\
\text { Ratio }(\%)\end{array}$ & $\begin{array}{c}\text { Theoretical Strain of First } \\
\text { Component to Break } \\
\text { (strain) }\end{array}$ & $\begin{array}{c}\text { Measured Strain of } \\
\text { Bamboo at Peak } \\
\text { (strain) }\end{array}$ & $\begin{array}{c}\text { Experimental } \\
\text { Failure Load } \\
\text { (kN) }\end{array}$ & $\begin{array}{c}\text { Theoretical Failure } \\
\text { Load } \\
\text { (kN) }\end{array}$ & $\boldsymbol{P}_{\text {exp } / \mathbf{P}_{\text {theory }}}$ \\
\hline Control & 100 & 0.0052 & 0.0031 & 152.4 & 155.1 & 0.98 \\
\hline FCB-FRN-H & 33 & 0.0052 & 0.0065 & 223.3 & 245.5 & 0.91 \\
\hline SCB-FRN-H & 33 & 0.0052 & 0.0065 & 210.8 & 245.5 & 0.86 \\
\hline FCB-GRT-H & 33 & 0.0035 & 0.0025 & 226.1 & 208.4 & 1.08 \\
\hline SCB-GRT-H & 33 & 0.0052 & 0.0048 & 143.3 & 152.3 & 0.94 \\
\hline FCB-EPX-I & 32 & 0.0052 & 0.0058 & 601.1 & 824.4 & 0.73 \\
\hline
\end{tabular}

\section{Conclusions}

In this study, unprecedented bamboo-based composite structural members were proposed and tested under compression until failure. The results of this study show that engineered bamboo, made of small diameter bamboo culms, can replace their carbon-intensive counterparts in constructions industry made of concrete, steel, and aluminium, without leading to deforestation of existing forests around the world. The proposed specimens were able to benefit from the advantageous mechanical properties of bamboo components while covering the natural material's flaws through efficient composite action with the matrices. The composite members introduced advantages in terms of strength, ductility, stiffness and absorbed energy when compared to the control column consisted of a non-composite bamboo bundle. Prediction equations were proposed to calculate the compressive capacity of the bamboo composite members in a rather precise manner. Based on the results of the current research study, the following major conclusions can be drawn:

- The proposed bamboo-composite systems, except for that of SCB-GRT-H specimen, can significantly enhance the compressive strength of bamboo columns when compared to the non-composite control specimen. In this study, the average gain in compressive capacity reaches $42.4 \%$ for bamboo and furan composite columns. The full culm bamboo and gout composite specimen reached $48.4 \%$ gain, whereas, the split culm bamboo and gout composite specimen failed to provide any gain in compressive capacity due to improper composted action between split bamboo and grout. The gain in the specimen with an epoxy matrix and improved confinement was the remarkable value of $294.4 \%$.

- The furan-based specimens presented an excellent recovery characteristic by almost returning from their extremely bent shape with $34^{\circ}$ rotation of the longitudinal axis at the ultimate to a residual $4^{\circ}$ out of straightness after the load was removed.

- The SCB-FRN-H represented the greatest amount of ductility between the tested specimens in terms of $D I$ with ductility index equal to 1.58 . The FCB-EPX-I did not represent ductile behaviour and failed in a brittle manner.

- The control specimen reached the greatest specified ductility index considering its lighter weight compared to other specimens $(S D I=0.971 / \mathrm{kg})$. Among the composite specimens, the SCB-FRN-H reached the greatest SDI equal to $0.641 / \mathrm{kg}$, which was due to its ductile behaviour and rather lightweight.

- Among the tested specimens, the FCB-GRT-H was the specimen, which represented the greatest axial stiffness with a $73 \%$ increase in the axial stiffness increase over the control column. The specimen SCB-GRT-H showed the lowest axial stiffness which corresponded to a $29 \%$ decrease in the axial ductility when compared to the control specimen.

- The specimen with the greatest amount of endured energy was the FCB-EPX-H with $A E$ equal to $4634.0 \mathrm{~J}$. The specimen with the least amount of energy absorption was the control specimen with $A E$ equal to $986.2 \mathrm{~J}$.

- The two specimens with the greatest specified absorbed energy were FCB-EPX-H and FCB-FRN-H specimens with $1.18 \mathrm{~J} / \mathrm{gr}$ and $0.90 \mathrm{~J} / \mathrm{gr}$, respectively. Considering the rather heavyweight of the 
grout-based specimens, they represented the least amount of $S A E$ among all specimens, i.e., $0.41 \mathrm{~J} / \mathrm{gr}$ and $0.17 \mathrm{~J} / \mathrm{gr}$ for FCB-GRT-H and SCB-GRT-H, correspondingly.

Author Contributions: Conceptualization, A.M.; methodology, A.M.; specimen fabrication, J.A. and J.T.M.N.; data interpretation, A.M.; validation, A.M.; formal analysis, A.M.; investigation, J.A. and J.T.M.N.; resources, A.M. writing-original draft preparation, A.M.; writing-review and editing, A.M.; visualization, A.M.; supervision, A.M.; and project administration, A.M. All authors have read and agreed to the published version of the manuscript.

Funding: This research received no external funding.

Acknowledgments: The authors acknowledge Transfurans Chemicals BVBA donation of Biorez 141010 and technical support on the resin application. The authors thank Jean Hall to fund the research costs of this study. The efficient collaboration of Stuart Patterson (engineering laboratory team leader), Gareth Wear (senior laboratory technician) and Michael Finlay (heavy structures laboratory technician) in conducting the tests is acknowledged.

Conflicts of Interest: The authors declare no conflict of interest.

\section{References}

1. Ogendal, A.S. Large-Deformation Behaviour of Thermoplastics at Various Stress States: An Experimental and Numerical Study. Ph.D. Thesis, Norwegian University of Science and Technology, Trondheim, Norway, 2012.

2. Javadian, A.; Wielopolski, M.; Smith, I.F.C.; Hebel, D.E. Bond-behavior study of newly developed bamboo-composite reinforcement in concrete. Constr. Build. Mater. J. 2016, 122, 110-117. [CrossRef]

3. United Nations World Urbanization Prospects. Department of Economic and Social Affairs, Population Division; The 2018 Revision Technical Report; United Nations World Urbanization Prospects: New York, NY, USA, 2018.

4. van der Lugt, P. Design Interventions for Stimulating Bamboo Commercialization: Dutch Design Meets Bamboo as a Replicable Model. Ph.D. Thesis, Delft University of Technology, Delft, The Netherlands, 2008.

5. Dowling, D.A.; Ramakrishnan, V. Green Gas Removal; Royal Society and Royal Academy of Engineering: London, UK, 2018.

6. United Nations Environment Global Status Report. Towards a Zero-Emission, Efficient, and Resilient Buildings and Construction Sector; United Nations Environment Global Status Report: Nairobi, Kenya, 2017.

7. Nunes, L. Nonwood bio-based materials. In Performance of Bio-Based Building Materials; Jones, D., Brischke, C., Eds.; Elsevier: Amsterdam, The Netherlands, 2017; pp. 97-186.

8. Hidalgo, H.G.; Amador, J.A.; Alfaro, E.J.; Quesada, B. Hydrological climate change projections for Central America. J. Hydrol. 2013, 495, 94-112. [CrossRef]

9. Bystriakova, N.; Kapos, V.; Stapleton, C.; Lysenko, I. Bamboo Biodiversity: Information for Planning Conservation and Management in the Asia-Pacific Region; Unep-Wcmc/Inbar: Beijing, China, 2003.

10. Wysocki, W.P.; Clark, L.G.; Attigala, L.; Ruiz-Sanchez, E.; Duvall, M.R. Evolution of the bamboos (Bambusoideae; Poaceae): A full plastome phylogenomic analysis. BMC Evol. Biol. 2015, 15. [CrossRef]

11. Clark, L.G. Bambusoideae in Poaceae, in Longhi-Wagner H (Editor) Flora Fanerogâmica do Estado de São Paulo, Volume I, [Includes collaboration with Londoño X, (Eremocaulon, Guadua), Longhi-Wagner H, and de Oliveira RP, (Olyra, Parodiolyra), and Sendulsky T, (Merostachys); Hucitec: São Paulo, Brazil, 2001; pp. 21-49.

12. Trujillo, D.J.A.; Lopez, L. Bamboo material characterisation. In Nonconventional and Vernacular Construction Materials; Harries, K.A., Sharma, B., Eds.; Elsevier: Amsterdam, The Netherlands, 2016; pp. 365-392.

13. Zea Escamilla, E.; Habert, G. Regionalizing the environmental impact of bamboo-based buildings by integrating life cycle assessment with geographic information systems: A comparative case-study in Colombia. In Proceedings of the 10th World Bamboo Congress, Damyang, Korea, 17-22 September 2015.

14. Akwada, D.R.; Akinlabi, E. Bamboo use in Construction Industry: How Sustainable is it? In Proceedings of the DII-2015 Conference on Infrastructure Development and Investment Strategies for Africa, Livingstone, Zambia, 16-18 September 2015.

15. Osorio, L.; Trujillo, E.; Van Vuure, A.; Verpoest, I. Morphological aspects and mechanical properties of single bamboo fibres and flexural characterization of bamboo/epoxy composites. J. Reinf. Plast. Compos. 2011. [CrossRef]

16. Wang, F.; Shao, J.; Keer, L.M.; Li, L.; Zhang, J. The effect of elementary fibre variability on bamboo fibre strength. Mater. Des. J. 2015, 75, 36-142. [CrossRef]

17. Sukmawan, R.; Takagi, H.; Nakagaito, A.N. Strength evaluation of cross-ply green composite laminates reinforced by bamboo fiber. Compos. Part B 2016, 84, 9-16. [CrossRef] 
18. Sharma, B.; Gatóo, A.; Bock, M.; Ramage, M. Engineered bamboo for structural applications. Constr. Build. Mater. 2015, 81, 66-73. [CrossRef]

19. Trujillo, D.J.A.; Malkowska, D. Empirically derived connection design properties for Guadua bamboo. Constr. Build. Mater. 2018, 163, 9-20. [CrossRef]

20. Chung, K.F.; Yu, W.K. Mechanical properties of structural bamboo for bamboo scaffoldings. Eng. Struct. 2002, 24, 429-442. [CrossRef]

21. Lobovikov, M.; Paudel, S.; Piazza, M.; Ren, H.; Wu, J. World Bamboo Resources: A Thematic Study Prepared in the Framework of the Global Forest Resources Assessment 2005; Food and Agriculture Organisation of the United Nations (FAO): Rome, Italy, 2007; p. 75.

22. Sharma, B.; Gatóo, A.; Bock, M.; Mulligan, H.; Ramage, M. Engineered bamboo: State of the art. Proc. Inst. Civil Eng. 2014. [CrossRef]

23. Xiao, Y.; Zhou, Q.; Shan, B. Design and construction of modern bamboo bridges. J. Bridge Eng. 2010, 15, 533-541. [CrossRef]

24. Ghavami, K.; Garcia, J. Building with Bamboo. Inst. Civil Eng. Available online: https://www.ice.org.uk/ news-and-insight/the-civil-engineer/march-2017/building-with-bamboo (accessed on 12 September 2019).

25. Shen, L.; Yang, J.; Zhang, R.; Shao, C.; Song, X. The benefits and barriers for promoting bamboo as a green building material in China-An integrative analysis. Sustainability 2019, 11, 2493. [CrossRef]

26. Harries, K.A.; Sharma, B.; Richard, M.J. Structural use of full culm bamboo: The path to standardization. Int. J. Arch. Eng. Constr. 2012, 1, 66-75. [CrossRef]

27. Sharma, B.; Gatóo, A.; Ramage, M. Effect of processing methods on the mechanical properties of engineered bamboo. Constr. Build. Mater. 2015, 83, 95-101. [CrossRef]

28. Harries, K.A.; Bumstead, J.; Trujillo, D.J.A. Geometric and material effects on bamboo buckling behaviour. In Structures and Building-Proceedings of the Institution of Civil Engineers the Institution of Civil Engineers; Institution of Civil Engineers: London, UK, 2016; p. 33.

29. Huang, Z.; Sun, Y.; Musso, F. Assessment of bamboo application in building envelope by comparison with reference timber. Constr. Build. Mater. 2017, 156, 844-860. [CrossRef]

30. ISO 22157 Bamboo Structures-Determination of Physical and Mechanical Properties of Bamboo Culms-Test Methods; International Organization for Standardization: Geneva, Switzerland, 2019; p. 32.

31. Dixon, P.G.; Gibson, L.J. The structure and mechanics of moso bamboo material. J. R. Soc. Interface 2014, 11, 20140321. [CrossRef] [PubMed]

32. Lo, T.Y.; Cui, H.Z.; Leung, H.C. The effect of fiber density on strength capacity of bamboo. Mater. Lett. 2004, 58, 2595-2598. [CrossRef]

33. Schmitt, C.R. Polyfurfuryl alcohol resins. Polym. Plast. Technol. Eng. 2008, 3, 121-158. [CrossRef]

34. Foruzanmehr, M.; Elkoun, S.; Fam, A.; Robert, M. Degradation characteristics of new bio-resin based-fiber-reinforced polymers for external rehabilitation of structures. J. Compos. Mater. 2015. [CrossRef]

35. Tumolva, T.; Kubouchi, M.; Sakai, T. Evaluating the carbon storage potential of furan resin-based green composites. In Proceedings of the 17th International Conference on Composite Materials, Edinburgh, UK, 27-31 July 2009.

36. Crossley, R.; Schubel, P.; Stevenson, A.; Moreira, M. The development and processing of a sustainable fully bio- derived polyfurfuryl alcohol matrix flax fibre prereg. In Proceedings of the ECCM15-15th European Conference on Composite Materials, Venezia, Italy, 24-28 June 2012.

37. Czifrák, K.; Lakatos, C.; Karger-Kocsis, J.; Daróczi, L.; Zsuga, M.; Kéki, S. One-pot synthesis and characterization of novel shape-memory poly( $\varepsilon$-Caprolactone) based polyurethane-epoxy co-networks with diels-alder couplings. Polymers 2018, 10. [CrossRef] [PubMed]

38. Yekani Fard, M. Nonlinear Inelastic Mechanical Behavior of Epoxy Resin Polymeric Materials. Ph.D. Thesis, Arizona State University, Tempe, AZ, USA, 2011; p. 192.

(C) 2020 by the authors. Licensee MDPI, Basel, Switzerland. This article is an open access article distributed under the terms and conditions of the Creative Commons Attribution (CC BY) license (http://creativecommons.org/licenses/by/4.0/). 